нию с носителями МР-2 и МР-3, и может быть рекомендован в качестве транспортных действующих веществ при конструировании лекарственных средств и требует дальнейших исследований.

Ключевые слова: крысы, олигодезоксинуклеотиды, полимеры, гемопоэз, аминотрансфераза, креатинин.

Susol Nataiya, Petruch I., Cech Bogdan, Ostapiv Dmytro, Vlizlo Vasulii. Hematologic and Biochemical Values of Blood Laboratory Rats After Injection of New Polymeric Carriers of Nucleotides. Polymeric carriers are providing direction, delivering of nucleotides and play the role of one of the most important tools in antysens therapy. However, we have a problem with a toxic effects of polymers on animals. Therefore, of particular relevance acquire research and development of new polymeric carriers and to study their effects on organism.

We have been studied the influence of the new-synthesized carriers MP-27, MP-2 and MP-3 on hematological and biochemical parameters of blood white rats. Established that the injection of polymers MP-2 and MP-3 results in a decrease of hematopoietic function and change percentage of leukocytes. Carrier MP-27 causes the least effect on blood values of laboratory rats. Was noted increase in the urea concentration, which probably indicates about the dysfunction of the kidneys after injection polymers and MP-2, MP-3. Values of activity ALT and AST also grew up, after the introduction of polymer MP-2 and MP-3; it is means, probable, about short-term functionality burden on the liver. Hence, MP-27 polymeric carrier is a low toxic compared to carriers MP-2 and MP-3, and he can be recommended as the transporter of active substances in the design of drugs and requires further investigation.

Key words: rat, nucleotides, polymers, hematopoiesis aminotransferase, creatinine.

Стаття надійшла до редколегії 16.09.2016 р.

УДК 612.18

\author{
Марія Татаренко, \\ Сергій Данилов, \\ Микола Макарчук
}

\title{
Оцінка взаємозв'язку невізуальних рухів очей і функціональної асиметрії мозку людини під час виконання вербальних завдань
}

Проаналізовано характер взаємозв'язку невізуальних рухів очей та функціональної асиметрії мозку людини. Установлено, що невізуальні рухи очей уліво та вправо не пов'язані з рівнем розвитку сенсомоторної асиметрії мозку обстежуваних. В обстежуваних із різним коефіцієнтом функціональної асиметрії мозку достовірною $\epsilon$ різниця в кількості невізуальних рухів очей уверх та вниз.

Ключові слова: функціональна асиметрія мозку, невізуальні рухи очей, вербальні завдання.

Постановка наукової проблеми та її значення. На сьогодні зібрано багато фактичного матеріалу, який свідчить про те, що рухи очей $\epsilon$ відображенням багатьох пізнавальних та емоційних психічних процесів, які відбуваються в мозку людини. Зокрема, рух очей використовується як інструмент для вивчення функціональної асиметрії мозку людини, оскільки, у середині минулого століття дослідники помітили, що в процесі формулювання відповіді на поставлене запитання обстежувані відводять свій погляд. Такий рух очей Bakan (1969) назвав спряженим латеральним рухом очей $[1 ; 2]$. Проте Ehrlichman (2012) запропонував використовувати термін невізуальні рухи очей, уключаючи сюди і латеральні (уліво, управо), і вертикальні (униз, уверх) рухи очей. Невізуальні рухи очей $\epsilon$ такими, що не пов' язані безпосередньо зі сприйняттям зорової інформації [3].

Відомо, що рух очей управо або вліво контролюється діяльністю контрлатеральної півкулі в полі 8 за Бродманом. 3 огляду на це, рух очей управо або вліво дослідники пов'язували з відображенням процесів, які відбуваються в півкулі, протилежній напряму руху очей [4].

Аналіз досліджень цієї проблеми. На підтримку формулювання про зв'язок невізуальних рухів очей із функціональною асиметрією мозку слугують дані отримані Kinsbourne (1972). У своїх дослідах за допомогою прихованої відеокамери він записував рухи голови й очей студентів, які відповідали на питання експериментатора, котрий сидів позаду. Установлено, що напрям руху очей був пов' язаний із типом запитання. Індивід виявляв значну тенденцію рухів очей управо на вербальні запитання та вгору або вліво - на просторові. Незначними виявилися рухи очей на запитання математичного характеру. Ці відмінності встановлено для праворуких індивідів. У ліворуких лате-

( Татаренко М., Данилов С., Макарчук М., 2016 
ралізація погляду розподілена рівномірно, незалежно від типу поставленого питання [5]. Проте сьогодні уявлення про контроль рухів очей на рівні мозку значно змінилися й відомо вже щонайменше п'ять зон кори мозку, які беруть участь у контролі руху очей, тому потрібно переглянути твердження про жорсткий взаємозв' язок рухів очей із функціональною асиметрією мозку [6; 7].

Мета й завдання роботи - дослідження та оцінка взаємозв'язку невізуальних рухів очей та функціональної асиметрії мозку людини під час виконання вербальних завдань.

Матеріали й методи досліджень. У дослідженні брали участь 52 студенти Київського національного університету імені Тараса Шевченка віком від 18 до 21 року, із них 35 - жінки та 17 чоловіки. Для групи обстежуваних розраховували коефіцієнт функціональної асиметрії мозку та відеокамерою реєстрували напрям руху очей під час прослуховування обстежуваним тексту іноземною мовою і його переказу рідною мовою. Коефіцієнт функціональної асиметрії мозку на підставі виконання обстежуваним низки функціональних проб (Брагіна, Доброхотова) розраховували за формулою:

$$
K A=\left[\left(E_{n}-E_{l}\right) /\left(E_{n}+E_{l}+E_{o}\right)\right] \bullet 100,
$$

де $\mathrm{E}_{\text {п }}$ кількість проб, у яких переважає права половина тіла;

$\mathrm{E}_{\mathrm{л}}$ - кількість проб, у яких переважає ліва половина тіла;

$\mathrm{E}_{\mathrm{o}}$ - кількість проб, де перевага відсутня [8].

Коефіцієнт функціональної асиметрії мозку (КА) оцінювали як високий КА>50 і середній та низький КА<50. Оцінку напряму руху очей проводили за критерієм: рух очей уверх, униз, уліво, управо. Комбіновані напрями руху очей - уверх управо, уверх уліво, униз управо, униз уліво - відносили окремо (латеральні або вертикальні) до відповідної групи за зазначеним вище критерієм. Критерій оцінки напряму руху очей зображено на рис. 1.

Під час обробки отриманих даних усіх обстежуваних поділено на декілька груп за такими критеріями:

1) загальна група обстежуваних;

2) за коефіцієнтом функціональної асиметрії мозку: високий (>50) та низький і середній $(<50)$;

3) за приналежністю до статі.

Подальше порівняння результатів проведених досліджень відбувалося 3 урахуванням вищезазначених груп обстежуваних.

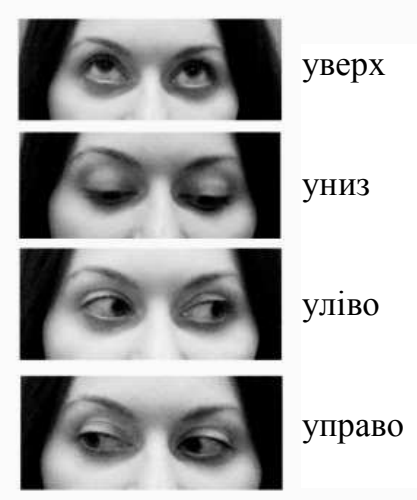

Рис. 1. Критерій оцінки напряму руху очей під час виконання вербального завдання

Статистичний аналіз даних здійснювали за допомогою пакета статистичних програм STATISTICA 7.0 (Stat-Soft, CША). Перевірку на нормальність виконували за допомогою критерію Лілієфора. За критерієм Лілієфора виявлено, що показники ненормально розподілені $(\mathrm{p} \leq 0,05)$. Для порівняння двох груп незалежних даних використовували критерій Мана-Вітні, залежних - критерій Вілкоксона. Кореляційний аналіз здійснювали за допомогою критерію Спірмена. Критичний рівень значущості під час перевірки статистичних гіпотез приймали як $\mathrm{p} \leq 0,05$. Для опису вибіркового розподілу вказували Мe [25; 75] (Ме - медіана; 25 i 75 нижній і верхній квартилі).

Виклад основного матеріалу й обгрунтування отриманих результатів дослідження. У загальній групі обстежуваних під час переказу тексту виявлено значуще більшу кількість рухів очей за напрямом уверх під час переказу тексту, ніж при його прослуховуванні (табл. 1, рис. 2). У загальній групі 
обстежуваних під час переказу та прослуховування тексту не спостерігали різниці в кількості рухів очей за напрямом уліво-управо. Це може бути пов'язано $з$ тим, що рухи очей уліво та вправо не $\epsilon$ показником сенсомоторної асиметрії.

Таблиия 1

Характер візуальних рухів очей обстежуваних загальної групи під час прослуховування та переказу тексту

\begin{tabular}{|c|c|c|c|c|}
\hline \multirow{2}{*}{$\begin{array}{c}\text { Прослуховування } \\
(n=52) \\
\text { к. } \mathbf{p .} 0 .\end{array}$} & H & B & $\boldsymbol{I}$ & II \\
\hline & $3[2 ; 6]$ & $0[0 ; 1]$ & $1[0 ; 4]$ & $1[0 ; 3]$ \\
\hline \multirow{2}{*}{$\begin{array}{c}\text { Переказ } \\
(n=52) \\
\text { к. p. о. }\end{array}$} & H & B & $\boldsymbol{I}$ & $\Pi$ \\
\hline & $3[1 ; 5]$ & $3[1 ; 4]$ & $3[2 ; 5]$ & $3[1 ; 4]$ \\
\hline
\end{tabular}

Примітка. к. р. о. - кількість рухів очей; $H$ - рух очей униз, В - рух очей уверх, Л - рух очей уліво, П - рух очей управо.

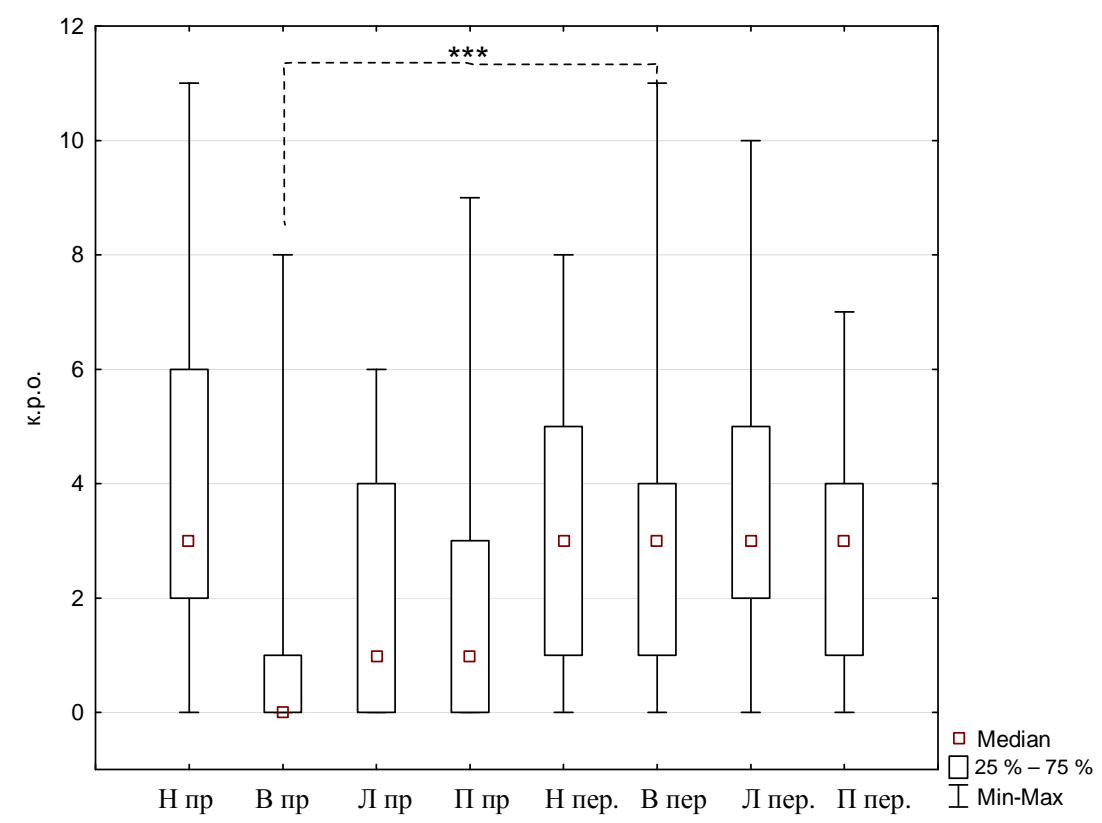

Рис. 2. Кількісна характеристика невізуальних рухів очей обстежуваних загальної групи під час виконання вербальних завдань

Примітка. *** - p<0,001, к. p. о. - кількість рухів очей; $H$ - рух очей униз, В - рух очей уверх, Л - рух очей уліво, П - рух очей управо, пр. - прослуховування, пер. - переказ.

У групі з коефіцієнтом асиметрії мозку КА>50 під час переказу тексту виявлено статистично значуще більшу кількість рухів очей уверх, ніж у групі з коефіцієнтом асиметрії КА<50 (табл. 3, рис. 4).

Таблиия 2

Характер невізуальних рухів очей в обстежуваних із коефіціснтом асиметрії <50 та >50 під час прослуховування й переказу тексту

\begin{tabular}{|c|c|c|c|c|c|c|c|c|}
\hline \multirow{2}{*}{$\begin{array}{c}\text { Прослуховування } \\
(n=17 / 32) \\
\text { к. p. о. }\end{array}$} & $\mathbf{H}_{<50}$ & $\mathbf{H}_{>50}$ & $\mathbf{B}_{<50}$ & $\mathbf{B}_{50}$ & $\boldsymbol{I}_{<50}$ & $\boldsymbol{I}_{>50}$ & $\Pi_{<50}$ & $\Pi_{>50}$ \\
\hline & $4[0 ; 11]$ & $3[0 ; 10]$ & $0,7[0 ; 8]$ & $0,7[0 ; 8]$ & $2[0 ; 6]$ & 5] & $1,9[0 ; 9]$ & $1,3[0 ; 5]$ \\
\hline \multirow{2}{*}{$\begin{array}{c}\text { Переказ } \\
(n=17 / 32) \\
\text { к. p. о. }\end{array}$} & $\mathbf{H}_{<50}$ & $\mathbf{H}_{>50}$ & $\mathbf{B}_{<50}$ & $\mathbf{B}_{>50}$ & $\boldsymbol{\Omega}_{<50}$ & $\boldsymbol{I}_{>50}$ & $\Pi_{<50}$ & $\Pi_{>50}$ \\
\hline & $3,4[0 ; 7]$ & $3,2[0,8]$ & $2,1[0 ; 6]$ & $3,4[0 ; 11]$ & $3,1[0 ; 7]$ & $3,7[1 ; 10]$ & $2,4[0 ; 6]$ & $3[0 ; 7]$ \\
\hline
\end{tabular}

Примітка. к. р. о. - кількість рухів очей; $H$ - рух очей униз, В - рух очей уверх, Л - рух очей уліво, П - рух очей управо, <50-коефійієнт асиметрії <50, >50- коефіцієєнт асиметрї > 50. 


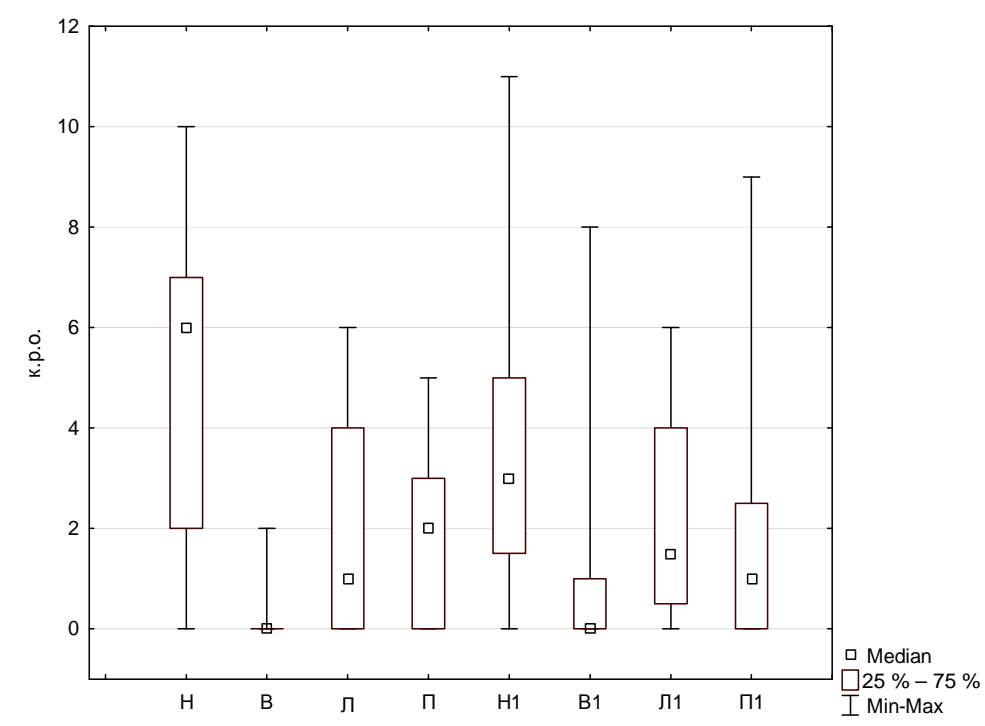

Рис. 3. Аналіз кількості рухів очей у групах із коефіиієнтом асиметрії <50 ma >50 під час прослуховування тексту

Примітка. к. р. о. - кількість рухів очей; коефіиієнт асиметрії <50: $H$ - рух очей униз, В - рух очей уверх, Л - рух очей уліво, П - рух очей управо; коефіцієнт асиметрії > 50: H1 - рух очей униз, В1 - рух очей уверх, Л1 - рух очей уліво, П1 - рух очей управо.

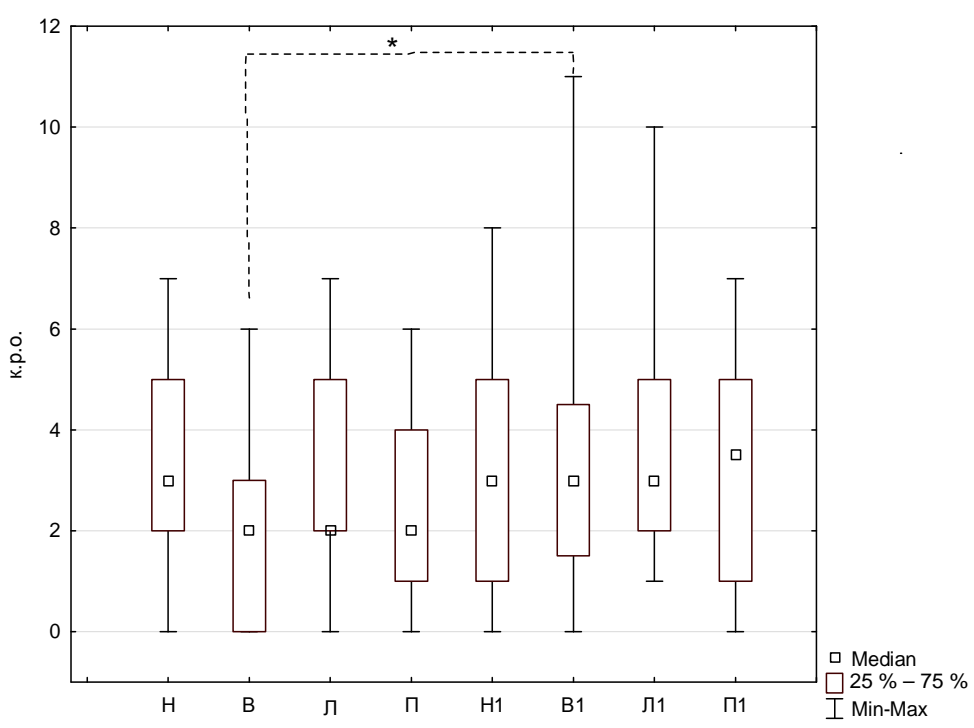

Рис. 4. Кількість рухів очей у обстежуваних із коефіцієнтом асиметрї <50 та >50під час переказутексту

Примітка. * - p<0,05, к. p. о. - кількість рухів очей; коефічієнт асиметрї <50: Н-рух очей униз, В - рух очей уверх, Л - рух очей уліво, П - рух очей управо; коефіцієнт асиметрії > 50: Н1 - рух очей униз, В1 - рух очей уверх, Л1 - рух очей уліво, П1 - рух очей управо.

Ми вважаємо, що рухи очей уверх у цьому випадку - це показник доступу та активації інформації, релевантної завданню. Поясненням до цього може бути двобічний зв'язок лобної кори й таламічних ядер. Серед них - інтраламінарні та дорзомедіальні ядра (також залучені до процесів пам'яті) у функціональному відношенні відіграють важливу роль в активаційній системі мозку. До того ж, згідно з клінічними даними, при ураженні зазначених ядер спостерігають порушення спряжених рухів очних яблук уверх [9; 10]. Вірогідно, в обстежуваних із КА>50 рухи очей уверх можуть бути відображенням міжпівкульного обміну інформації при переказі тексту.

Не виявлено статистично значущої різниці в напряму руху очей серед чоловіків і жінок під час переказу та прослуховування тексту (табл. 3 , рис. 5,6 ). Невізуальні рухи очей ми розглядаємо як відображення 
Характер невізуальних рухів очей в обстежуваних жінок та чоловіків під час прослуховування та переказу тексту

\begin{tabular}{|c|c|c|c|c|c|c|c|c|}
\hline \multirow{2}{*}{$\begin{array}{c}\text { Прослуховування } \\
(n=35 / 14) \\
\text { к. p. о. } \\
\end{array}$} & $\mathbf{H}_{\text {жін. }}$ & $\mathbf{H}_{\text {чол. }}$ & $\mathbf{B}_{\text {жін. }}$ & В чол. $_{\text {ч. }}$ & $\boldsymbol{I}_{\text {жін. }}$ & $\boldsymbol{\Omega}_{\text {чол. }}$ & $\Pi_{\text {жін. }}$ & $\Pi_{\text {чол. }}$ \\
\hline & $4[0 ; 11]$ & $3[0 ; 10]$ & $0,7[0 ; 8]$ & $0,7[0 ; 8]$ & $2[0 ; 6]$ & $1,8[0 ; 5]$ & $1,9[0 ; 9]$ & $1,3[0 ; 5]$ \\
\hline \multirow{2}{*}{$\begin{array}{c}\text { Переказ } \\
(n=35 / 14) \\
\text { к. p. о. }\end{array}$} & $\mathbf{H}_{\text {жін. }}$ & $\mathrm{H}_{\text {чол. }}$ & $\mathbf{B}_{\text {жін. }}$ & В чол. $_{\text {ч. }}$ & $\boldsymbol{I}_{\text {жін. }}$ & $\boldsymbol{J}_{\text {чол. }}$ & $\Pi_{\text {жін. }}$ & $\Pi_{\text {чол. }}$ \\
\hline & $2,8[0 ; 8]$ & $2,6[0 ; 5]$ & $3,4[0 ; 11]$ & $2[0 ; 17]$ & $3,9[1 ; 10]$ & $2,6[0 ; 9]$ & $2,7[0 ; 6]$ & $3,1[0 ; 7]$ \\
\hline
\end{tabular}

Примітка. к. р. о. - кількість рухів очей; $H$ - рух очей униз, В - рух очей уверх, Л - рух очей уліво, П - рух очей управо, жін. - жінки, чол. - чоловіки.

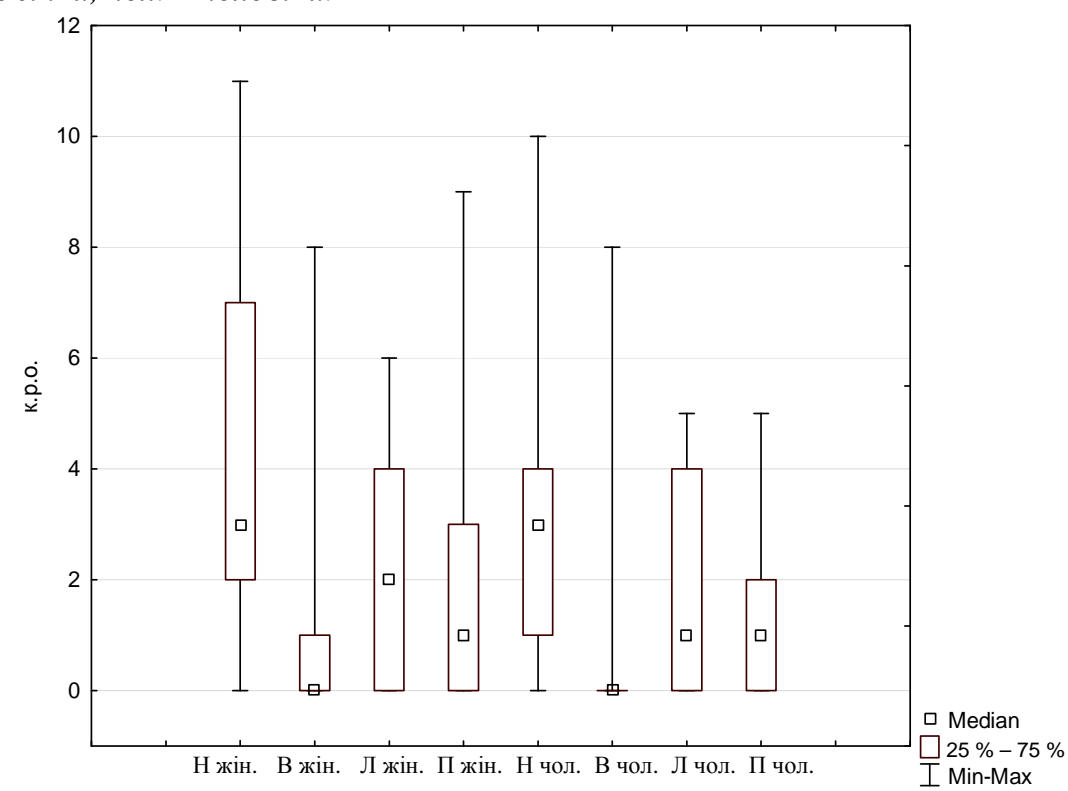

Рис. 5. Кількістьрухів очей жінок та чоловіків під час прослуховування тексту

Примітка. к.р.о. - кількість рухів очей; $H$ - рух очей униз, В - рух очей уверх, Л - рух очей уліво, П - рух очей управо, жін. - жінки, чол. - чоловіки.

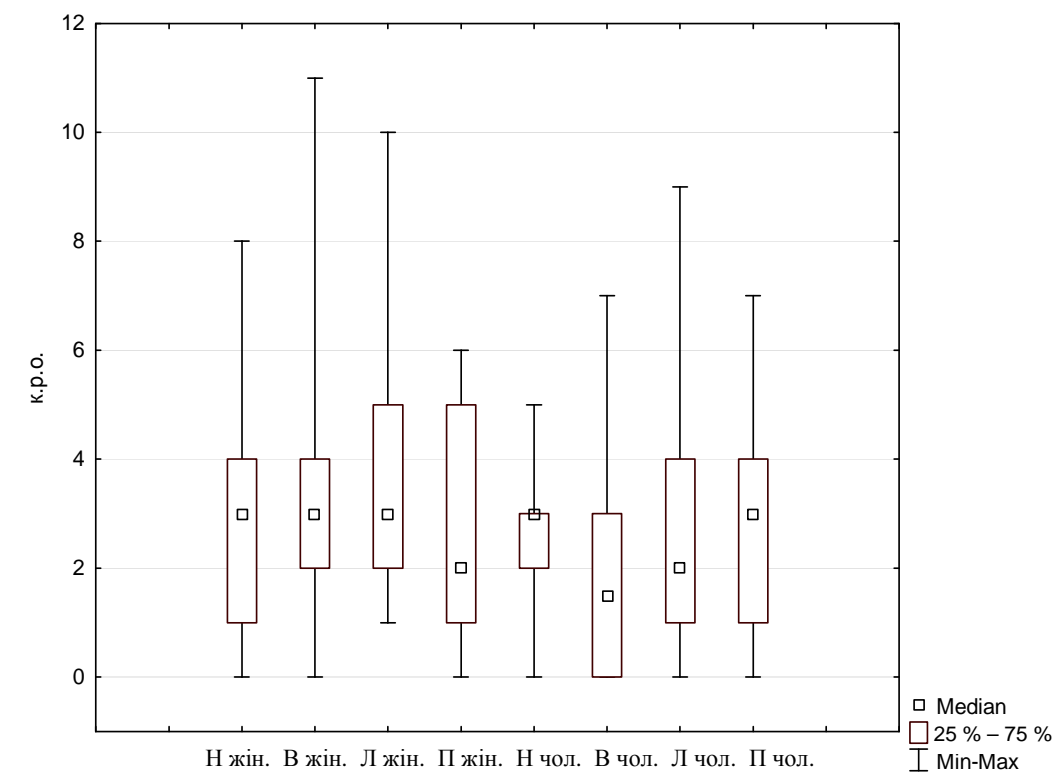

Рис. 6. Кількість невізуальних рухів очей жінок та чоловіків під час переказу тексту

Примітка. к. р. о. - кількість рухів очей; $H$ - рух очей униз, В - рух очей уверх, Л - рух очей уліво, П - рух очей управо, жін. - жінки, чол. - чоловіки. 
формування активаційного процесу при виконанні конкретних завдань, тому відсутність відмінностей між чоловіками й жінками може свідчити про відсутність принципових міжстатевих відмінностей в активаційних процесах під час виконання наших вербальних завдань.

Висновки та перспективи подальшого дослідження. У всіх обстежуваних під час переказу тексту достовірно переважають невізуальні рухи очей уверх, порівняно з такими рухами очей при прослуховуванні тексту, тоді як за цих умов кількість невізуальних рухів очей уліво-управо у двох тестах не відрізнялася.

Під час переказу тексту в обстежуваних із середнім і високим коефіцієнтом асиметрії мозку кількість рухів очей уверх є більшою, ніж в осіб із низьким коефіцієнтом асиметрії.

У чоловіків та жінок у всіх тестах не виявлено достовірної різниці в характері невізуальних рухів очей.

\section{Джерела та література}

1. Misra I. Revisiting the relationship between hand preference and lateral eye movement / I. Misra, D. Suar, K. M. Mandal // Psychological Test and Assessment Modeling. - 2010. - Vol. 52. - P. 261-271.

2. Bakan P. Hypnotizability, laterality of eye-movements and functional brain asymmetry / P. Bakan // Perceptual and Motor Skills. - 1969. - Vol. 28. - P. 927-932.

3. Ehrlichman H. Why do people move their eyes when they think? / H. Ehrlichman, D. Micic // Current Directions in Psychological Science. - 2012. - Vol. 21, № 2. - P. 96-100.

4. Wilson J. S. Saccadic eye movement parameters in normal subjects / J. S. Wilson, P. Glue, D. Ball, J. D. Nutt // Electroencephalography and Clinical Neurophysiology. - 1993. - Vol. 86. - P. 69-74.

5. Gur E. R. Conjugate lateral eye movements as an index of hemispheric activation / E. R. Gur // Journal of Personality and Social Psychology. - 1975. - Vol. 31, № 4. - P. 751-757.

6. Lync J. C. Cortico-cortical networks and cortico-subcortical loops for the higher control of eye movements / J. C. Lync, J.-R. Tian // Progress in Brain Research. - 2006. - Vol. 151. - P. 461-501.

7. Lync J. C. A short history of the study of the interaction between oculomotor control and shifts of visual attention / J. C. Lync // Cognitive Critique. - 2010. - Vol. 2. - P. 43-74.

8. Брагина Н. Н. Функциональные асимметрии человека / Н. Н. Брагина, Т. А. Доброхотова. - 2-е изд., перераб. и доп. - М. : Медицина, 1988. - 240 с.

9. Виничук С. М. Трепет Изолированный инфаркт таламуса: клинические синдромы, диагностика, лечение и исход / С. М. Виничук, М. М. Прокопив // Укр. мед. часопис : наук.-практ. загальномед. часоп. - 2012. № 2. - С. 87-93.

10. Clark J. M. Vertical gaze palsies from medial thalamic infarctions without midbrain involvement / J. M. Clark, W. A. Gregory // Stroke. - 1995. - Vol. 26, № 8. - P. 1467-1470.

Татаренко Мария, Данилов Сергей, Макарчук Николай. Оценка взаимосвязи невизуальных движений глаз и функциональной асимметрии мозга человека при выполнении вербальных заданий. Проанализирован характер взаимосвязи невизуальных движений глаз и функциональной асимметрии мозга человека. Установлено, что невизуальные движения глаз влево и вправо не связаны с уровнем развития сенсомоторной асимметрии мозга испытуемых. У лиц с разным коэффициентом функциональной асимметрии мозга достоверной является разница в количестве невизуальных движений вверх и вниз.

Ключевые слова: функциональная асимметрия мозга, невизуальные движения глаз, вербальные задания.

Tatarenko Mariya, Danylov Sergii, Makarchuk Mykola. Evaluation of Relationship of Non-visual eye Movements and Functional Brain Asymmetry in Human During Verbal Task Fulfillment. The character of relationship of non-visual eye movements and functional brain asymmetry in human was analyzed. It was discovered that leftward and rightward non-visual eye movements are not related to a level of subjects' sensomotor development. The difference in number of upward and downward non-visual eye movements is reliable for subjects with different level of functional brain asymmetry.

Key words: functional brain asymmetry, non-visual eye movements, verbal tasks

Стаття надійшла до редколегії 29.09.2016 р. 